\title{
PRAXIS EN EL PASADO: APROXIMACIONES A LA INTERVENCIÓN EN EL PATRIMONIO ARQUITECTÓNICO DE LIMA ${ }^{(*)}$
}

\author{
PRAXIS IN THE PAST: APPROACHES TO THE INTERVENTION OF THE ARCHITECTURAL \\ HERITAGE IN LIMA
}

\author{
PAMELA BONILLA POLANCO ${ }^{(*)}$ \\ Fecha de recepción: 01 de abril de 2015 \\ Fecha de aprobación: 15 de mayo de 2015
}

\begin{abstract}
RESUMEN
Un monumento integrante del patrimonio cultural es una construcción de gran valor histórico, artístico o científico que pertenece a un determinado grupo humano. Por tanto, es un deber garantizar su salvaguarda para el conocimiento de las generaciones futuras. En el caso particular de Lima, una gran cantidad de edificios históricos se encuentran en estado de deterioro; si no se actúa en el presente, estas corren el riesgo de desaparecer. Por lo tanto, el quehacer patrimonial se considera un tema pendiente de estudio, desarrollo y ejecución desde distintos campos profesionales. Por ello, la presente investigación analizará el aspecto arquitectónico-urbanista de esta situación, indagando modelos de intervención en el patrimonio edificado desde un enfoque conceptual, principista, metodológico y propositivo. Desde el punto de vista de cada arquitecto restaurador, se exponen intervenciones reconocibles en el espacio urbano, con distintos grados de intromisión, que han sido realizadas en los últimos años. Se desarrollan los siguientes casos: la Casona de San Marcos, cuyos patios fueron partícipes de episodios históricos distintos; el antiguo Mercado Municipal de Barranco, en tanto hito urbano representativo de la memoria barranquina; y el centro cultural Ccori Wasi, elemento integrador del conjunto urbano de la Av. Arequipa.
\end{abstract}

\section{PALABRAS CLAVE}

Intervención, patrimonio arquitectónico

\begin{abstract}
A monument of cultural heritage is a construction that has an important value in aesthetic, scientific and historical terms for a specific group of people and, therefore, its safeguard must be guaranteed in order to preserve it for the future generation's knowledge. In the particular case of Lima, a large number of such buildings are damaged and under the risk of disappearing if no action is soon taken. Consequently, this is an outstanding issue of study that involves different professional fields. Thus, the following article will analyze the urbanist-architectural aspect and investigates models of intervention in the built heritage from a conceptual, methodological and proactive approach. From the viewpoint of each of the architects, three recognizable interventions in urban space will be presented, each with a varying degree of interference, which have been made recently. We have developed the following cases: St Mark's Mansion, whose patios were the location of different historical issues; Barranco's old Municipal Market, an important and representative building regarding citizen's memory; and Cori Wasi Cultural Centre, an integrating element of the urban complex of the Arequipa Avenue.
\end{abstract}

\section{KEYWORDS}

Intervention, architectural heritage

(*) El artículo "Praxis en el pasado" fue desarrollado a partir de la investigación titulada "Aproximaciones a la intervención en el patrimonio arquitectónico de Lima", desarrollada en el Taller de Investigación 2009-2, curso a cargo del Prof. Dr. Wiley Ludeña Urquizo y su equipo de docentes y asistentes, en el marco académico de la Facultad de Arquitectura y Urbanismo de la Pontificia Universidad Católica del Perú.

(**) Pamela Bonilla Polanco (Lima, 1989) estudió Arquitectura y Urbanismo en la Pontificia Universidad Católica del Perú (2006 - 2012), donde se tituló con el proyecto de recuperación del paisaje y espacios públicos Jardín Botánico en Moyobamba (2013). Cursó la especialización Diseño y Manejo de Áreas Verdes y Arboricultura Urbana en la Universidad Nacional Agraria La Molina (2014), diplomado en el que ejercería la docencia en el año 2015. Habilitada desde el año 2014 (CAP 16048), ha realizado investigaciones sobre temas de paisaje, arquitectura y patrimonio. Actualmente se desempeña como arquitecta proyectista independiente. 
La ciudad de Lima ha sido, y es escenario de distintos procesos culturales y momentos trascendentales para la historia del país. Por ello posee una gran cantidad de monumentos patrimoniales; lamentablemente, muchos de estos se encuentran en estado de abandono. Si bien los recursos públicos destinados a su conservación son escasos, muchas veces estos son empleados en intervenciones sin ningún criterio de análisis, pues la reconstrucción aún figura en el imaginario común de las personas como la acción necesaria. No obstante, el campo de la restauración y conservación involucra muchos más criterios particulares según cada proyecto, de modo que las acciones pertinentes no se limitan a la mera reconstrucción del inmueble. Por lo tanto, conocer distintas propuestas arquitectónico-restauradoras brinda herramientas de reflexión sobre la praxis en torno a la conservación de monumentos. A continuación, se analizarán tres casos de intervención en el patrimonio arquitectónico de Lima, para lo cual es necesario definir algunos conceptos previos.

\section{Patrimonio}

Según el Instituto Nacional de Cultura (2009), el patrimonio es el conjunto de bienes, tanto materiales como inmateriales, acumulados a lo largo del tiempo, que unifican la nación generando identidad. Es decir, el patrimonio tiene la función activa de estrechar los lazos entre los distintos pueblos que integran un país a partir de elementos comunes del pasado. Sin embargo, en el Perú esta capacidad no ha sido explotada al máximo, especialmente en lo referente al patrimonio edificado.

De acuerdo a la Carta de Venecia (1964), el patrimonio arquitectónico "comprende la creación arquitectónica aislada, así como el conjunto urbano o rural que da testimonio de una civilización particular..." (p. 1) y, por ello, tiene muchísimo potencial, pues basta recorrerlo para conocer gran parte del testimonio del pasado en cada monumento. Por lo tanto, la mejor salvaguarda posible consiste en su correcta adaptación a un uso público. En palabras de David Cerna (2007), el patrimonio arquitectónico debe someterse a las reglas de la economía urbana y la sostenibilidad económica, al igual que cualquier estructura construida. Es decir, debe adaptarse estos edificios a nuevos usos que les permitan generar ingresos para hacer sostenible su conservación en el tiempo.

Adaptar un edificio patrimonial a un nuevo uso demanda, en primer lugar, una investigación que permita determinar las acciones que es necesario realizar, es decir, que establezca el carácter de la intervención. Según Hayakawa (2001), la intervención en el patrimonio, las medidas que se toman para enmendar los daños ocurridos, se diferencian por el nivel de intromisión que tienen en un monumento arquitectónico. Las más comunes son la conservación y la restauración: la primera se define como el cuidado y mantenimiento de las edificaciones, mientras que la segunda consiste en su correcta lectura y la correspondiente restitución de la apariencia de los elementos dañados.

\section{La Carta de Venecia}

La Carta de Venecia (1964) es un documento que estableció los principios comunes que deben regir la conservación y la restauración, cuyos objetivos son principalmente salvaguardar el valor artístico e histórico de los monumentos. En él se plasman, esencialmente, principios de la Teoría del Restauro. Además, constituye el primer documento que opera como referencia normativa e ideológica para los restauradores peruanos.

La carta, en primer lugar, señala que la conservación de monumentos debe orientarse a convertirlos en edificaciones útiles para la sociedad; no obstante, para conseguirlo no se debe alterar la ordenación o decoración de estos. Excepcionalmente, si bien por regla general deben respetarse los estilos sobrepuestos a lo largo del tiempo, aquellos añadidos que afecten aspectos importantes pueden ser retirados. Por otro lado, se puede hacer uso de técnicas o materiales contemporáneos para asegurar la vida del monumento. Sin embargo, los elementos que reemplacen partes inexistentes o excesivamente deterioradas deben distinguirse notablemente de los originales y, a la vez, integrarse armoniosamente con el conjunto. 
En relación a los lugares monumentales, se indica utilizar los mismos preceptos, pues "deben ser objeto de atenciones especiales a fin de salvaguardar su integridad y de asegurar su saneamiento, su tratamiento y su realce" (Carta de Venecia, 1964, p.3).

\section{Restauradores Peruanos}

La restauración y la conservación se establecieron como una práctica relativamente común aproximadamente en la década de los años 20, cuando se manifiesta la primera ley a favor del patrimonio cultural en la historia del Perú. Sin embargo, esta ley no configuró ni consolidó de ninguna manera una política cultural de restauración, de tal modo que la práctica del restaurador en Lima se circunscribió a la labor de quienes Hayakawa (2001) define como "empíricos". Los empíricos realizaban la práctica de ensayo y error, de tal modo que se capacitaban a sí mismos mediante la experiencia y el aprendizaje propio. Este periodo, que comprende desde 1920 hasta 1964, se caracteriza por girar en torno a la reconstrucción con el objetivo de rehacer el inmueble de la forma que ellos suponían debía ser.

Luego se daría un nuevo periodo que Hayakawa (2001) conceptualiza como el de los "especialistas", que data desde 1964 hasta 1990. Para este grupo de arquitectos, la Carta de Venecia fue el instrumento ideológico más importante e influyente en su praxis. Este documento marcó un punto de inflexión respecto a la conservación del patrimonio en Lima: generó una ruptura ideológica, conceptual, profesional y generacional entre los entendidos con la aparición de nuevas prácticas de mano de los especialistas. Este grupo, cuya característica principal fue la aproximación metódica-científica de su perfil profesional, desarrolló los procesos de restauración mediante el estudio sistemático y específico de la historia, la tecnología, el arte y la arqueología.

Dicha era de la restauración en Lima fue impulsada por la aparición del Instituto Nacional de Cultura (INC), organismo que ha incentivado el desarrollo de la restauración y conservación del patrimonio, pero no ha tenido el protagonismo necesario.

\section{La Casona de San Marcos}

La Casona de San Marcos constituye uno de los más importantes monumentos del patrimonio arquitectónico de Lima, debido a su categórico valor histórico, su tipología de monasterio, su posterior adaptación a casa de estudios, su estratégica ubicación en el Centro Histórico, y su función social y cultural.

La restauración de este monumento consistió en un largo proceso que, patio por patio, ha ido poniendo en valor distintas cualidades que componen su arquitectura. Desde comienzos de los años 90 , se dio inicio a uno de los proyectos de recuperación más trascendentes de las últimas décadas, pues el extenso proceso de restauración de este edificio ofrecía una oportunidad óptima para la introducción y promoción de criterios contemporáneos sobre restauración y nuevo uso del patrimonio. A partir del año 2001, fueron los arquitectos Martin Fabbri y Ana Elisa Berenguel los encargados de las intervenciones aquí descritas.

En un inicio, la Casona de San Marcos fue construida, entre 1605 y 1613, para acoger un noviciado jesuita, y alcanzaría su máxima extensión hacia la primera mitad del siglo XVIII. De acuerdo a Burneo (2013), el vanguardismo intelectual y el poder económico de los jesuitas por ese entonces se evidencia en la distribución y funcionalidad del edificio. Dicha espacialidad, compuesta por patios y claustros secuenciales, se mantendría tras el destructivo sismo de 1746, pues se intervino y se reconstruyó la configuración original, tanto el emplazamiento de los patios como la disposición de los principales ambientes (Bonilla y Fuentes, 2009). 
devenir Vol. 2, N³, ENERO- JUNIO 2015, PP. 45-62 - ESTUDIOS | ISSN 2312-7570

UNIVERSIDAD NACIONAL DE INGENIERÍ, LIMA

Figura 1. Relleno: Planta de la Casona de San Marcos.

Fuente. Archivo personal Martin Fabbri, 2015.
Tras la expulsión de los jesuitas en 1767, el local sería ocupado por el Real Convictorio de San Carlos. Después, tras la Independencia, pasaría a ser propiedad del Colegio Mayor de San Carlos, para finalmente ser asignado a la Universidad Nacional Mayor de San Marcos (UNMSM) en 1867, momento desde el cual pasaría a conocerse como Casona de San Marcos. En cuanto al estado físico del edificio, en el año 1860, un proyecto de urbanización confinaría al conjunto dentro de la manzana que actualmente ocupa y, seguidamente, la guerra con Chile ocasionaría daños mayores que serían restaurados eventualmente. A través de todo este proceso, los patios principales no sufrirían mayores transformaciones espaciales. Fue en la segunda mitad del siglo XX cuando comenzaría un proceso acelerado de tugurización que conllevaría a un trágico deterioro, considerado irreversible (Burneo, 2013).

En ese contexto, el destino del viejo edificio de la Casona de San Marcos no parecía ser otro que sucumbir ante el abandono y, posteriormente, desaparecer. Sin embargo, en 1989, se formó un compromiso con el Gobierno Español para apoyar la restauración integral de este importante conjunto histórico y su adaptación como Centro Cultural de San Marcos. Un año más tarde, la Agencia Española de Cooperación Internacional del Desarrollo se unió a los esfuerzos del programa de preservación del patrimonio cultural, conformando una alianza estratégica con la UNMSM.

Durante cada una de estas etapas, la arquitectura del conjunto ha ido adaptándose de acuerdo al uso que se consideró necesario. Hoy funciona como un centro cultural abierto al público, compuesto por una secuencia de patios, entre los cuales se analizaron tres: el Patio de Ciencias, el Patio de Letras y el Patio de Derecho (Figura 1).

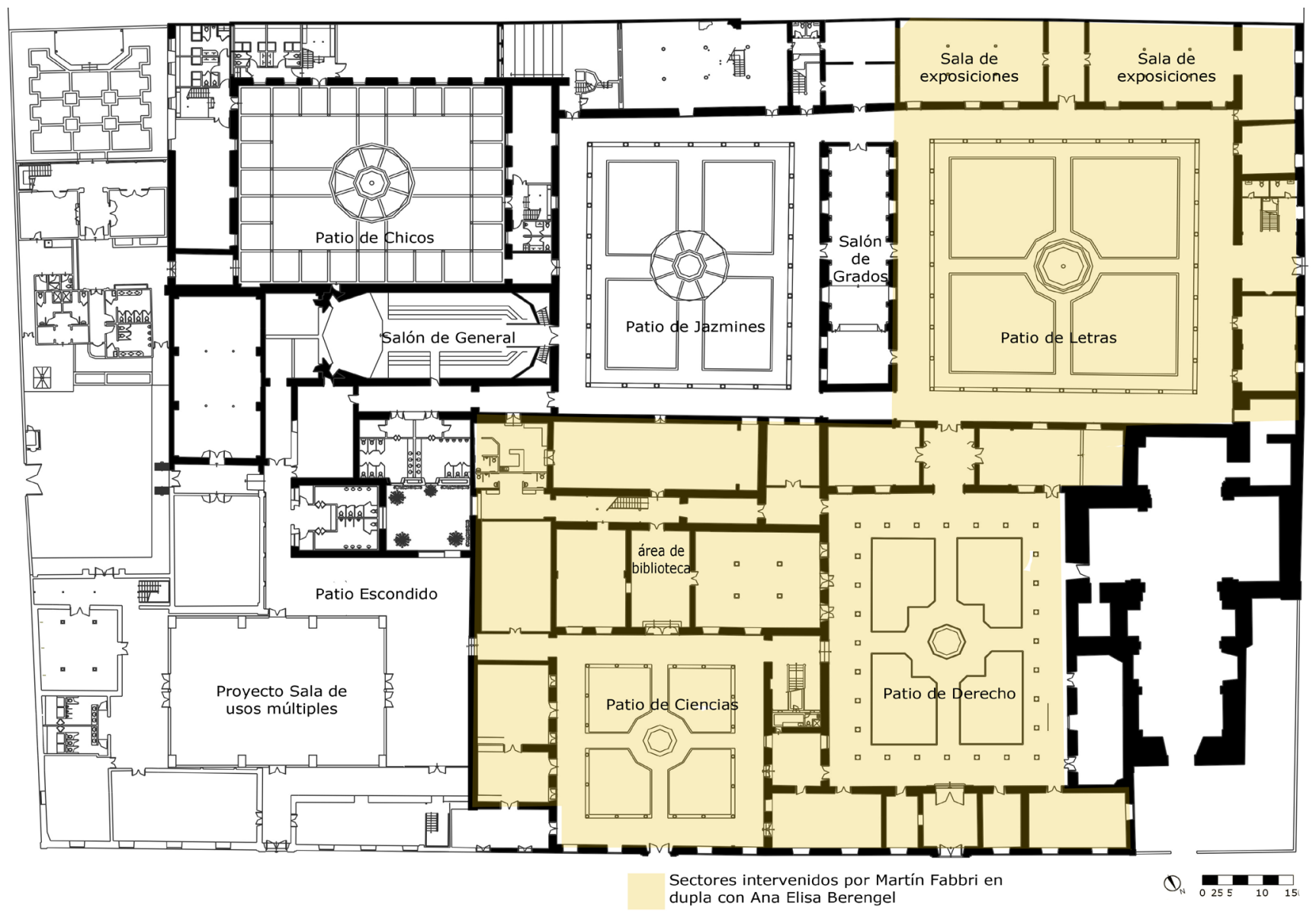


La Casona de San Marcos se presentó como un desafío a los restauradores, pues su presencia y significado se debe a una sucesión de agregados en el tiempo, lo cual complejizó el planteamiento desde el principio. Por lo tanto, primero se realizó un levantamiento físico e histórico del edificio, mediante el cual se halló importantes valores artísticos e históricos distintos en cada sector. Luego, trazando el objetivo de acortar los gastos de la entidad patrocinadora, se aplicaron conceptos planteados en la Teoría del Restauro y la Carta de Venecia. Finalmente, a través de un proceso crítico de todas las variables, se determinó con qué rango de intensidad se podía intervenir cada uno de los patios.

El objetivo del proyecto consistió en intervenir los patios menos históricos con mayor intromisión y acercarse a los más históricos de la manera más conservadora posible, con mínima acción, privilegiando el mantenimiento de lo existente.

El Patio de Ciencias o Patio de los Machos es uno de los patios con menor valor histórico. Fue edificado a mediados del siglo XVIII, como parte del proceso de reconstrucciones posteriores al terremoto del año 1746. Atravesó distintos cambios de uso a lo largo del tiempo y, en consecuencia, sufrió numerosas transformaciones. Se colocaron gran cantidad de agregados, se hicieron importantes modificaciones en las galerías, y se acondicionaron tabiquerías interiores y escaleras, lo que ocasionó graves problemas estructurales.

En vista de que el Patio de Ciencias tiene una trascendencia menor, los autores de la restauración se atrevieron a realizar mayores modificaciones. Por una parte, se retiraron cierres y paneles de las galerías superiores, elementos ajenos que habían ocasionado deterioros estructurales y afectaban la arquitectura prexistente. Por otra parte, se extrajo la escalera en esquina que había sido colocada en 1955 (Burneo, 2013), pues interrumpía el correcto y fluido desplazamiento por el patio. Se observa que los autores siguieron las pautas de la Carta de Venecia en cuanto a los añadidos, pues retiraron los elementos que no respetaban el trazado original del patio, lo cual permitió consolidar las circulaciones y el carácter arquitectónico inicial (Figura 2).

Igualmente, se hicieron modificaciones para mejorar la espacialidad del claustro interior. Se habilitó un bloque independiente en el hoy rescatado sector sur del patio para la Biblioteca España de las Artes. Además, se planteó recuperar los espacios abandonados que rodeaban el antiguo callejón, de modo que la intervención consistió en techarlo para convertirlo en un espacio de transición interior entre los ambientes que lo rodean (Figura 3).

En la planta de estado preintervención, se puede observar que las circulaciones hacia los recintos eran poco fluidas y que había varios espacios residuales, mientras que en el plano posintervención se observa una circulación mucho más ordenada, una ubicación más racional de los servicios higiénicos y un aprovechamiento total de los recintos.

Con esta nueva habilitación, se crearon nuevas circulaciones interiores que permiten una experiencia distinta. Este nuevo recorrido penetra en las estancias, discurre a través de los ambientes más íntimos de la casona y posibilita imaginar el otrora discurrir de los sanmarquinos. Si bien este planteamiento ha requerido modificaciones importantes en el monumento, los resultados propician una relación más íntima entre el edificio y el usuario.

Por otro lado, el Patio de Letras o Patio de los Naranjos es uno de los más representativos de la casona. Sus orígenes remontan al año 1613, época en la que contaba con talleres, depósitos y establos. Hacia 1910, ya propiedad universitaria, después de la reconstrucción posguerra, se amplió mediante la construcción de un segundo nivel, el cual cobijaría nuevas aulas para el alumnado. Años después, se cerraría dicha galería con ventanales de madera para albergar más aulas y salas de exposición.

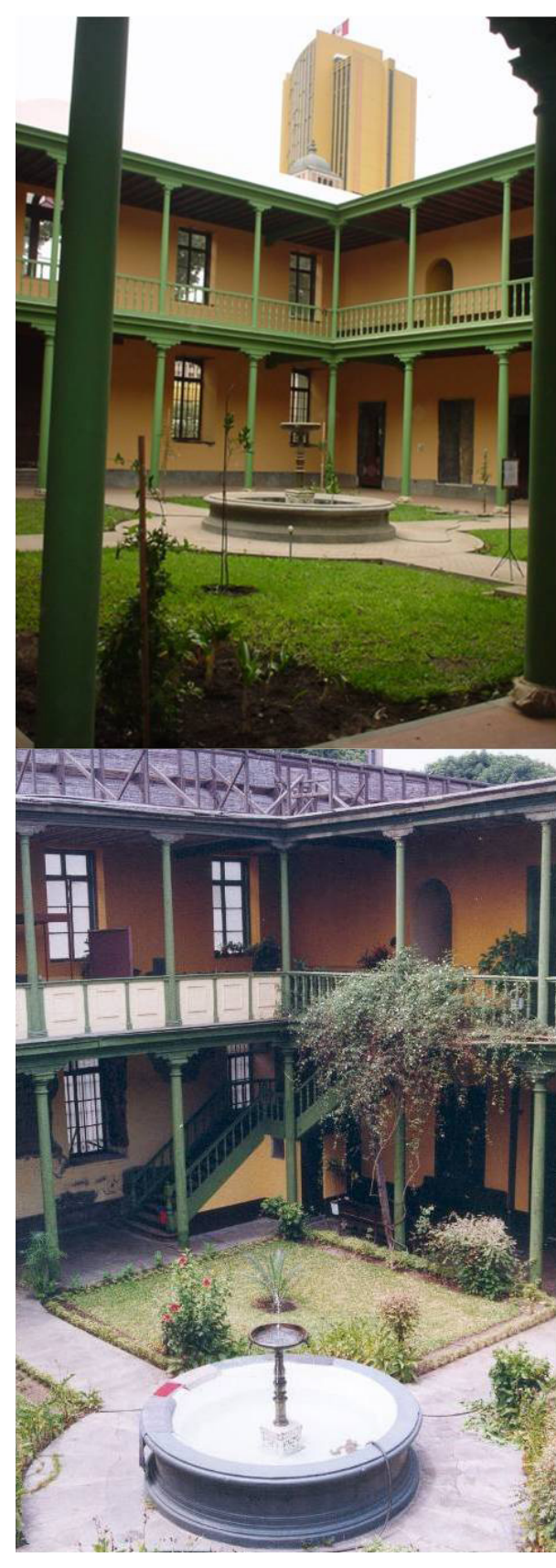

Figura 2. Estado pre y pos intervención del Patio de Ciencias.

Fuente. Archivo personal Martin Fabbri, 2015. 


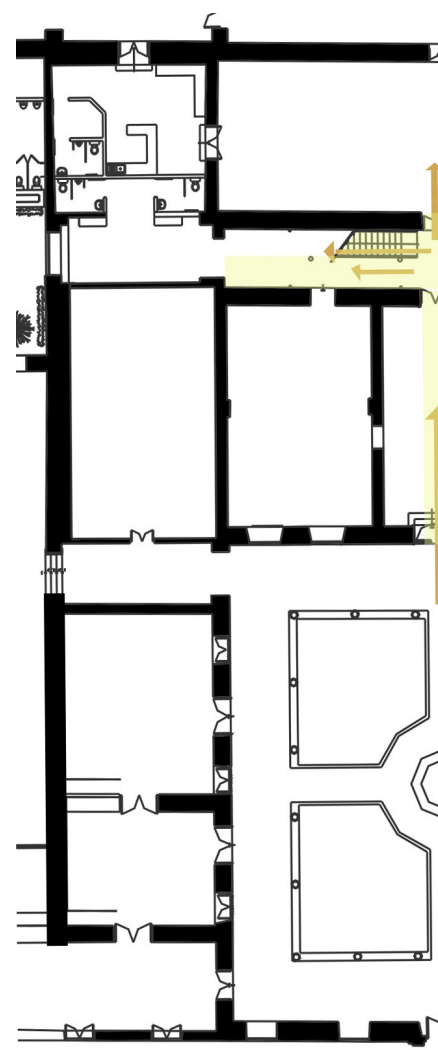

Zonas de circulación - Flujos habilitados
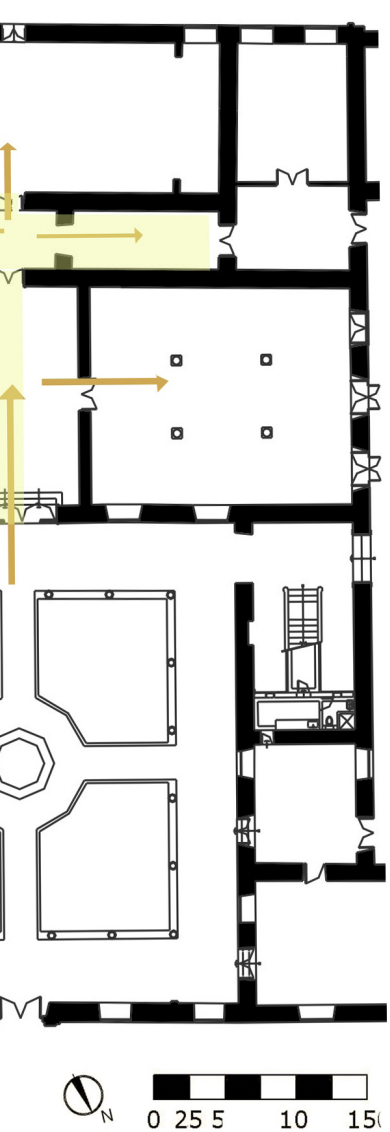

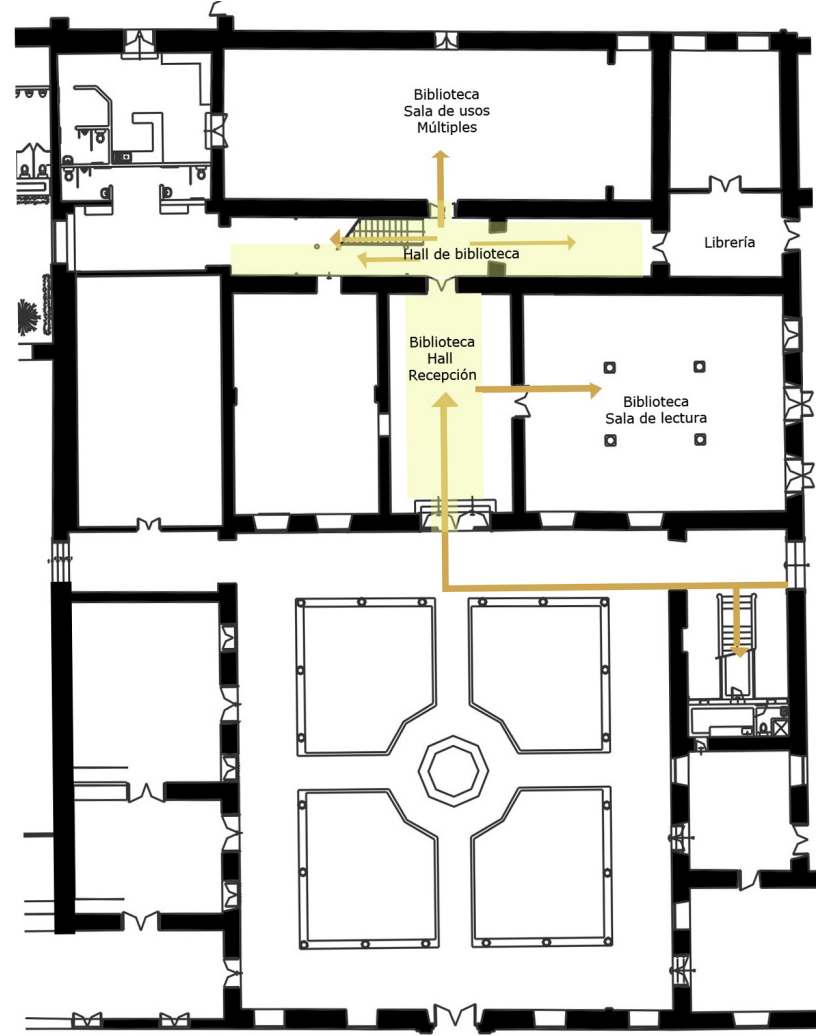

$\square$ Centralidades generadas: independiencia de usos - Circulaciones
Figura 3. Planta Patio de Ciencias. Fuente. Archivo personal Martin Fabbri, 2015.

Figura 4. Estado actual de la Sala de Exposiciones.

Fuente. Archivo personal Martin Fabbri, 2015.

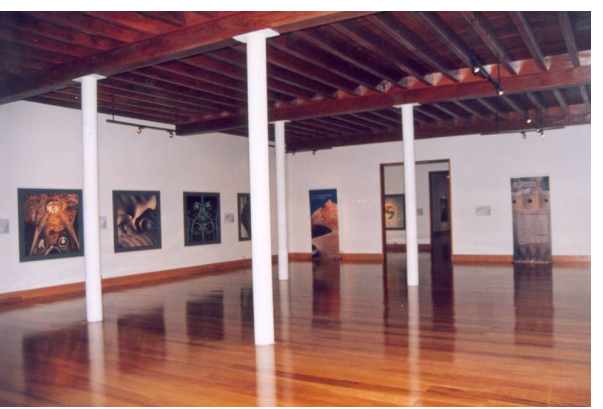

En el primer nivel del patio, se habilitaría una nueva área de museo para el centro cultural. Según Burneo (2013), los estudios previos a la restauración constataron que allí ya existían columnas aisladas de madera desde el siglo XIX. Por tanto, una buena manera de aprovechar la planta libre ya preestablecida era adaptar amplias salas para exposiciones temporales. Bajo esta premisa, se hicieron trabajos de conservación y consolidación estructural, durante los cuales se encontraron muchas columnas dañadas que tuvieron que ser reemplazadas por otras nuevas, de diferente material. De esta manera, se obtuvo un efecto contrastante entre el techo de viguetería de madera oscura auténtico y las nuevas columnas metálicas de color blanco. Como resultado, los materiales contemporáneos se identifican como intervenciones del tiempo presente y, asimismo, se mantiene la lógica estructural existente (Figura 4).

El Patio de Derecho, también conocido como Patio de los Maestros, es el de mayor valor histórico entre los tres, ya que es el único que se mantiene en su lugar original. Albergó dependencias y habitaciones de las principales autoridades que ocuparon el lugar, motivo por el cual ha sido un claustro de dos plantas desde tiempos del noviciado.

A los largo de su existencia, el Patio de Derecho no fue exento de modificaciones estructurales y arquitectónicas. Debido al crecimiento del alumnado durante el periodo universitario, se retiró una columna central de una de las galerías inferiores. Esta supresión se habría realizado, posiblemente, para mejorar el desplazamiento de los alumnos. Sin embargo, no se previó la carga puntual que ejercería la galería del segundo nivel. Con el paso del tiempo, las cornisas superiores se fueron deformando hacia la parte central, lo cual puso en riesgo de colapso la edificación (Figura 5). 

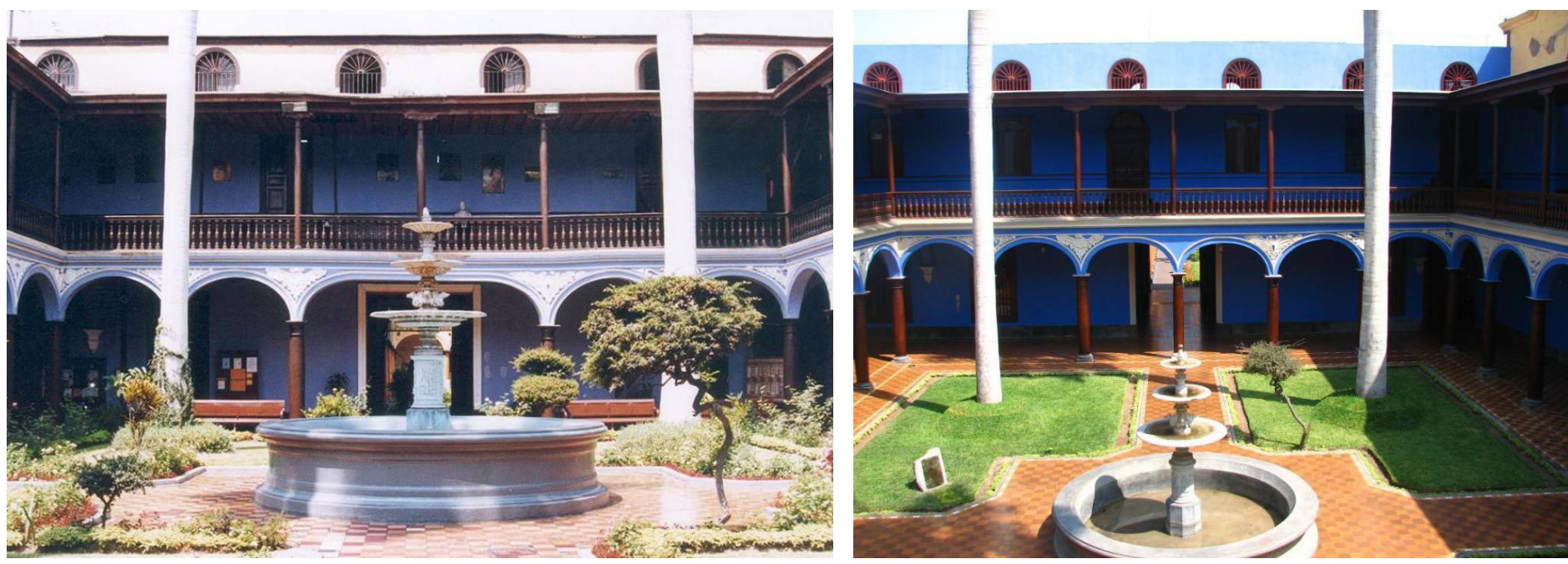

Por esta razón, la propuesta de restauración incluyó la recolocación de la columna desaparecida para afianzar la estructura del inmueble. Esta está elaborada en base a los mismos materiales tradicionales, pero presenta detalles que revelan su contemporaneidad, por ejemplo, la supresión de elementos decorativos e iconografías en la zona superior, y la distinción en el basamento mediante el empleo de piedra (Figura 6).

Esta medida es un ejemplo ilustrativo de conservación tanto de los valores artísticos como históricos del patio. Por un lado, la ausencia de la nueva columna debilitaba la estructura, perjudicaba la uniformidad de las galerías y distorsionaba la horizontalidad de las cornisas, mientras que, por otro lado, la sobriedad de la pieza agregada contrasta con las originales y se distingue como un elemento colocado en la actualidad.

Un concepto importante aplicado en la Casona de San Marcos es el enaltecimiento de su vocación cultural mediante la inclusión de elementos didácticos. Además, el edificio tiene un amplio carácter social, lo que asegura su supervivencia a lo largo del tiempo. Por consiguiente, Berenguel y Fabbri han dotado al edificio de un sentido pedagógico, de modo que genere un flujo continuo de visitantes, lo cual asegura un espíritu vivo en el monumento. Este rol educativo es en esencia la narración de la historia del edificio que los trabajos de intervención han ido descubriendo.

Los pisos aplicados al conjunto conforman un ejemplo elocuente, específicamente en el detalle de pavimentos expuestos en el Patio de Derecho. La evolución de usos se evidencia en la presencia de diferentes técnicas y materiales correspondientes a cada etapa histórica. Por ejemplo, está el canto rodado, que alguna vez acaparó por completo el patio, antes de la existencia de los jardines, lo que remonta a una época en la que fueran superficies amplias para que el alumnado pueda realizar reuniones concurridas y disertaciones al aire libre. Asimismo, se observa una sección de piso de cemento pulido de comienzos del siglo XX, y el adoquinado, expresión material de los años 30 (Figura 7).

Igualmente, cada patio ha exhibido distintos colores a lo largo del tiempo, de modo que bajo cada capa de color se encuentra otra de mayor antigüedad. Por ello, se realizaron trabajos de investigación mediante el empleo de escalas estratigráficas que dejan los colores descubiertos expuestos con la intención de que el público participe de una dinámica instructiva. De esta manera, Berenguel y Fabbri realizaron varios ejercicios para entender la evolución cromática, los cuales ahora son aprovechados como medio informativo y explicativo (Figura 8).
Figura 5. Patio de Derecho preintervención.

Fuente. Archivo personal Martin Fabbri, 2015.

Figura 6. Patio de Derecho posintervención.

Fuente. Archivo personal Martin Fabbri, 2015.

Figura 7. Detalle de pisos.

Fuente. Archivo personal Martin Fabbri, 2015.
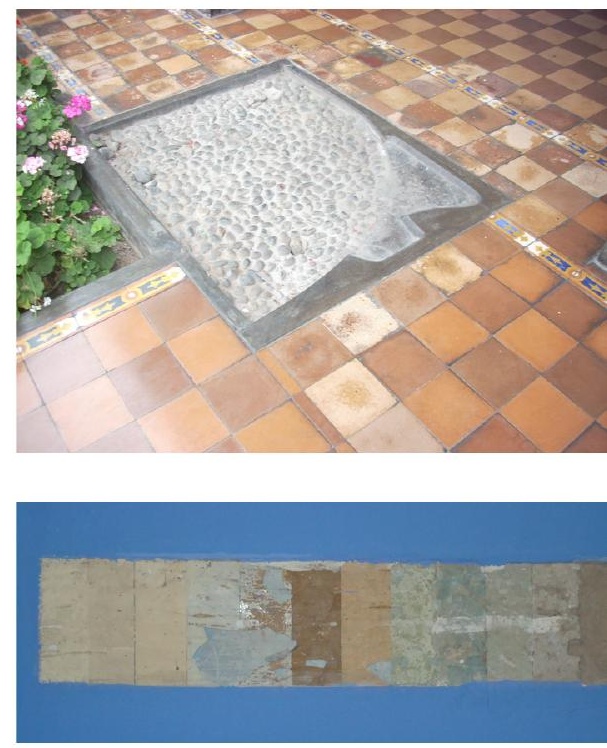

Figura 8. Escala estratigráfica de colores - Patio de Derecho.

Fuente. Archivo personal Martin Fabbri, 2015. 
devenir Vol. 2, N³, ENERO - JUNIO 2015, PP. 45-62 - EstudIOS | ISSN 2312-7570

UNIVERSIDAD NACIONAL DE INGENIERÍA, LIMA

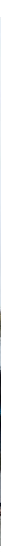

Figura 9. Panorámica del Parque Universitario y la Casona de San Marcos.

Fuente. Archivo personal Martin Fabbri, 2015.

Figura 10. Mercado Municipal de Barranco, 1924.

Fuente. Archivo personal Aldo Lértora, 2015.
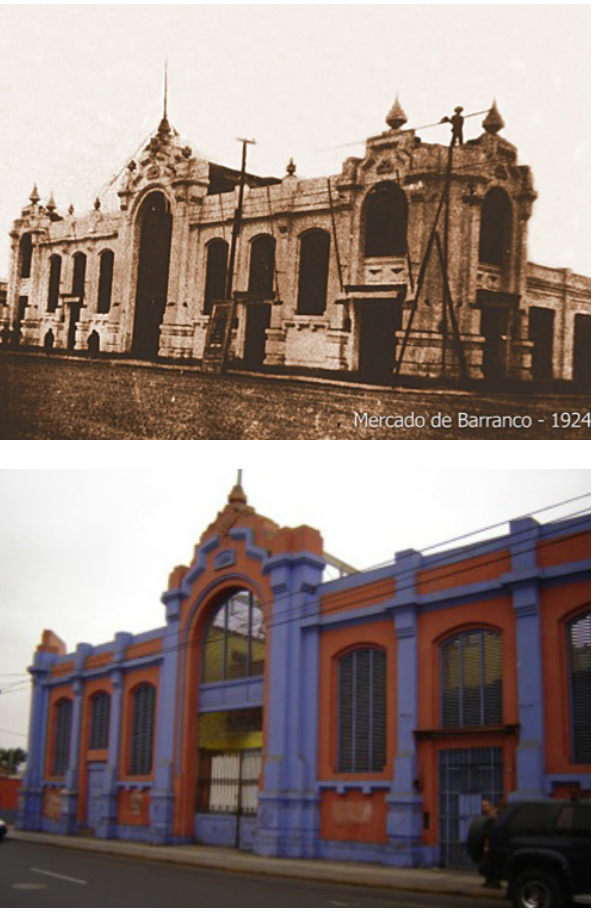

Figura 11. Mercado Municipal de Barranco preintervención.

Fuente. Archivo personal Aldo Lértora, 2015.
Esta función histórico-educativa se repite continuamente en el edificio de una forma coherente e interesante, que genera un circuito cultural a partir de la restauración del inmueble. Dotar al edificio de un sentido pedagógico que favorezca un uso continuo asegura la persistencia de un espíritu vivo en el monumento: “Esa conexión social que requiere hacer la arquitectura probablemente se tenga que lograr a partir de propuestas que sean innovadoras [...] un profesor me enseñó que restaurar es algo más". (M. Fabbri, comunicación personal, 25 de octubre de 2010). (Figura 9)

\section{Antiguo Mercado Municipal de Barranco}

El antiguo Mercado Municipal de Barranco está ubicado en uno de los conjuntos urbanos que más evoca la memoria limeña debido a su arquitectura, de gran trascendencia histórica y cultural.

Durante las primeras décadas del siglo XX, Barranco dejaría de ser solo un balneario importante para consolidarse como distrito. Así, el crecimiento del mismo abrió paso a nuevas construcciones, entre de las cuales figura el Mercado de Abastos de Barranco, inserto en la trama urbana desde el año 1924. Este edificio hito ejerce una influencia importante por su ubicación y monumentalidad, motivo por el cual el arquitecto restaurador Aldo Lértora fue encargado de su recuperación.

El estudio realizado (Lértora, 2001) reveló que el proyecto se atribuyó al arquitecto Ricardo de Jaxa Malachowsky y al contratista Santiago Harth Campbell, y fue ejecutado posteriormente por el Sr. Luis Razzeto entre junio de 1923 y febrero de 1924, con modificaciones mínimas al diseño inicial. Sin embargo, tras el terremoto del año 1940, el plan municipal reformuló la intersección de fachadas; por lo tanto, se colocaron chaflanes luego de retirar las esquinas del edifico, arriesgando así su estructura general como un núcleo macizo. Finalmente, hacia el final de la década de 1980, una nueva comitiva municipal amenazaría con demoler el inmueble, que se encontraba en estado ruinoso. Ello motivó al Instituto Nacional de Cultura, la entidad entonces pertinente, a declararlo como monumento del patrimonio arquitectónico de Barranco. Lamentablemente, esta condición de intangibilidad no contribuiría a subsanar el deterioro del edificio, debido a la falta de conservación y mantenimiento, ni a detener la proliferación de puestos de alimentos, que superarían doblemente la capacidad local. Como resultado, el caos, el desorden y el hacinamiento interno afectaron el entorno urbano colindante, por lo que finalmente el municipio remató el inmueble a una compañía privada de inversiones para ser adaptado a un edificio de supermercado (Figuras 10 y 11 ).

El estilo de este edificio se puede catalogar como ecléctico, pero incluye elementos de los inicios del art déco. Por otro lado, el tipo arquitectónico responde al de un mercado público: está conformado por un espacio central de gran altura, techado con una 
estructura de madera semiabierta, y un conjunto de tiendas, de menor altura, distribuidas a su alrededor, que definen el perímetro del mercado, el cual es solo atravesado por cuatro ingresos principales y dos secundarios. Al momento de la intervención, el deterioro se presentaba principalmente en los elementos estructurales y los detalles ornamentales (Figura 12).

Trazando el objetivo de rentabilizar el proyecto para el inversor, el arquitecto Lértora planteó esta intervención según los principios de la Teoría del Restauro y la Carta de Venecia; es decir, realizaría una evaluación para determinar los valores artísticos e históricos del monumento. Como resultado, se encontró con distintos aspectos tipológicos, arquitectónicos y urbanos del edificio que debían rescatarse. Tales aspectos, simultáneamente con los recursos y demandas del promotor, serían evaluados para tomar una postura final. La idea consistió en adaptar el monumento al uso de supermercado respetando los aspectos artísticos identificados.

En primer lugar, la imagen y monumentalidad del edificio se consideraron un atributo fundamental, pues el contexto inmediato se compone de residencias y construcciones pertenecientes a una escala más doméstica. Se reconoció la importancia del volumen arquitectónico para la trama urbana de Barranco, así que se planteó restaurar la fachada del edificio en su totalidad. Afortunadamente, dada la contundencia del monumento para el distrito, existía suficiente documentación fotográfica para hacer los trabajos de conservación y restauración de los elementos de fachada y los refuerzos estructurales.

Los trabajos de refuerzos consistieron en colocar columnas de concreto con cajuelas y planchas metálicas que arriostren cada cierto tramo de los muros, mientras que en las zonas de adobe se hicieron refuerzos con mallas. También se resanaron todos los efectos de los zócalos o molduras existentes, y se repusieron las faltantes. Asimismo, las puertas en fachada fueron restauradas en su totalidad; se retiraron las rejas o puertas enrollables que se habían agregado anteriormente. En otras palabras, se abolieron los agregados poco relevantes, se completaron los elementos faltantes y se resanaron las zonas afectadas con el objetivo de consolidar la belleza del inmueble (Figura 13).

En lo que respecta al interior del edificio, se respetó la estructura general: el espacio central de múltiple altura iluminado cenitalmente y la envolvente de muros de puestos de venta conformando el perímetro del mercado. La propuesta adaptó la zona central como una gran superficie de exhibición de productos en góndolas y, de igual manera, dispuso en dos niveles las zonas de depósitos, apoyo, tiendas complementarias y servicios en los espacios circundantes.

En las zonas perimétricas, se invirtieron todas las aperturas de los puestos exteriores hacia el interior. Para ello se ampliaron los vanos que unían las tiendas con el espacio interno, mientras que se cerraron los que daban hacia las calles. En estos recintos se ubicarían servicios y tiendas complementarias que aprovechasen los muros existentes, a excepción de la crujía paralela a la calle Génova, donde se eliminó la mayoría cantidad de muros divisorios para consolidar un área de depósitos y apoyo.

En el segundo piso se dispuso un ambiente en mezzanine para usos múltiples que comunique con los servicios higiénicos y más áreas de apoyo para el supermercado. Al intervenir este entrepiso, se mantuvieron las viguetas existentes y el machihembrado; no obstante, se reemplazaron los elementos en mal estado. De igual manera, para reforzarlo, se colocó una losa colaborante que se apoya sobre nuevas columnas metálicas de color blanco, que permitirían el paso de instalaciones sanitarias y eléctricas (Figura 14).

En la zona central se encuentra el espacio arquitectónico más valorado. Se trata de un gran espacio compuesto por un techo de pilastras, viguetas y vigas de madera, distribuidas a distintas alturas, que manejan un ingreso de luz cenital excepcional. Sin embargo, el deterioro ocasionó la desaparición del machihembrado superior, el retiro de algunos tramos de viguetas y la infección de algunas columnas portantes.

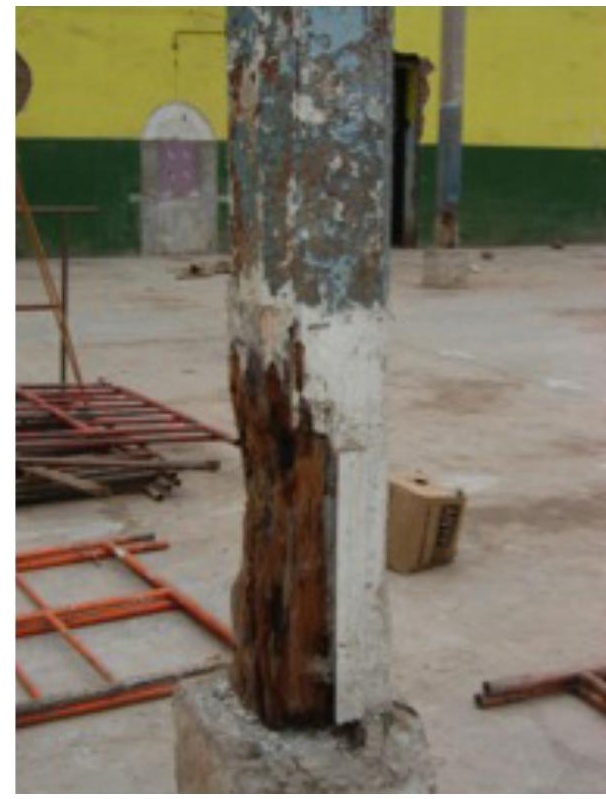

Figura 12. Columna corroída por falta de mantenimiento.

Fuente. Archivo personal Aldo Lértora, 2015.

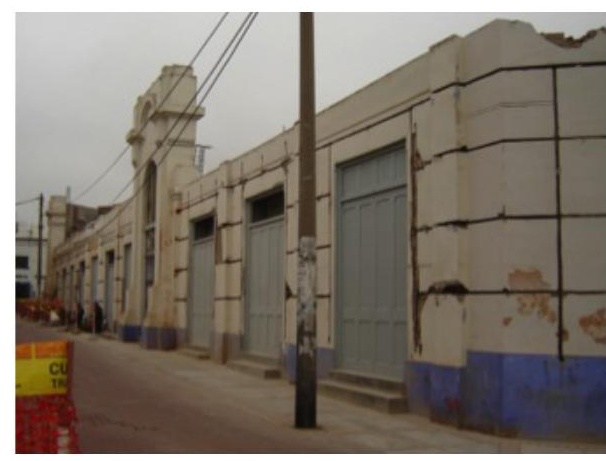

Figura 13. Refuerzos en muros de adobe.

Fuente. Archivo personal Aldo Lértora, 2015. 

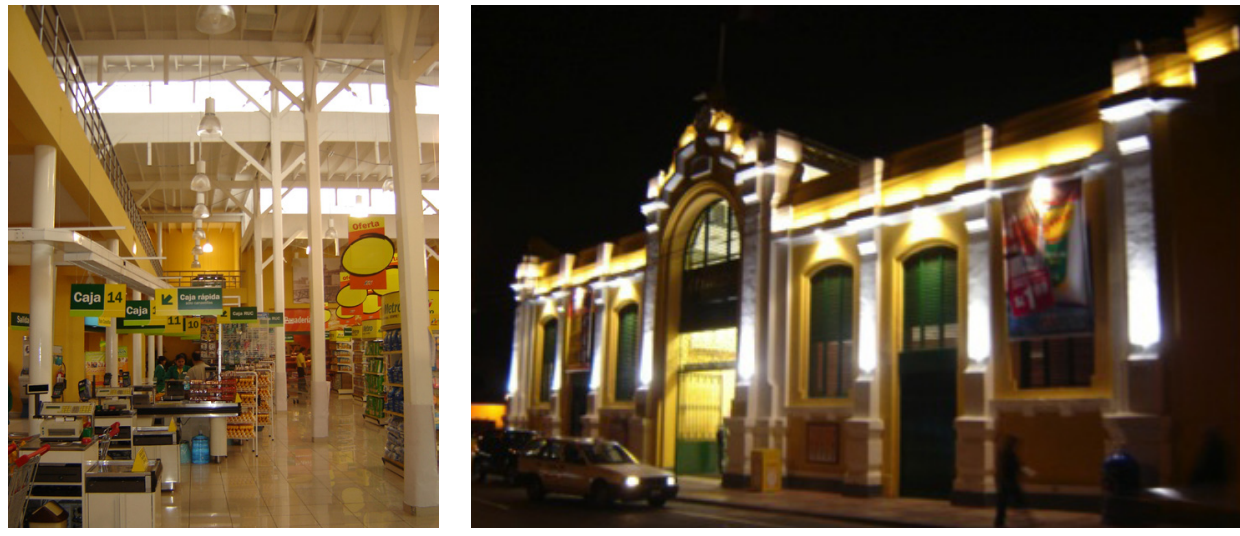

Como resultado, el edificio destaca por su monumentalidad y se consolida como un hito en el paisaje urbano de Barranco. Genera nuevas relaciones con el entorno gracias a su revalorización pues "inyectar modernidad a esa magnitud, no solo invierte en recuperar el edificio, sino todo el espacio público circundante. Ese es un punto importante: cómo se contribuye a recuperar el entorno a raíz de intervenciones puntuales de intervención privada" (A. Lértora, comunicación personal, 22 de octubre de 2010).

\section{El Centro Cultural Ccori Wasi}

Durante la era de la República Aristocrática, se establecieron barrios de veraneo hacia el sur de Lima, en los distritos actualmente conocidos como Barranco y Chorrillos. Como consecuencia de ello, se creó la avenida Leguía, hoy avenida Arequipa, con el propósito de unir esos barrios sureños con el Centro Histórico. Nuevas residencias se acomodaron a lo largo de este nuevo eje, lo cual generó el tejido urbano complementario que hoy conforman los distritos de Miraflores, San Isidro y Lince. Un paisajismo romántico del siglo XIX se imponía en las secciones viales ajardinadas y en las manzanas compuestas por viviendas de familias adineradas.

Sin embargo, durante las últimas décadas, este carácter se ha ido perdiendo pues muchas de estas casonas han desaparecido para convertirse en torres de departamentos. Si bien aún muchas residencias se encuentran en un óptimo estado de conservación, la demanda de suelo urbano sigue ejerciendo presión sobre aquellos inmuebles descuidados, entre ellos el actual Centro Cultural Ccori Wasi.

Originalmente fue una casona bifamiliar de carácter neocolonial construida en los años 40. Luego fue acondicionada como clínica y posteriormente, adquirida por la Universidad Ricardo Palma. Al inicio, fue un importante edificio para la institución, ya que allí fue firmada el acta fundacional en el año 1969 y, además, albergó varias facultades. Con el paso del tiempo, el inmueble fue destinado a las carreras de Biología y Arquitectura sucesivamente; después se convirtió en un centro de idiomas y, finalmente, pasó a ser local de unas pocas oficinas administrativas, algunos salones de clase y varios ambientes en abandono.
Figura 17. Contraste entre materiales.

Fuente. Archivo personal Aldo Lértora, 2015.

Figura 18. Iluminación nocturna. Fuente. Archivo personal Aldo Lértora, 2015.
Figura 19. Panorámica preintervención.

Fuente. Archivo personal Enriq0ue Bonilla, 2015.

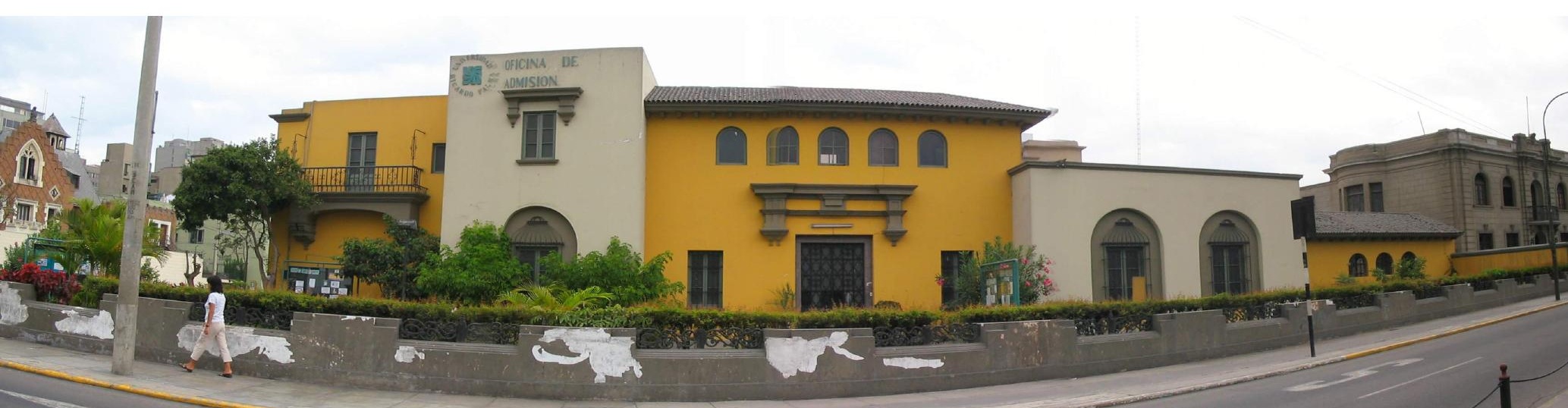




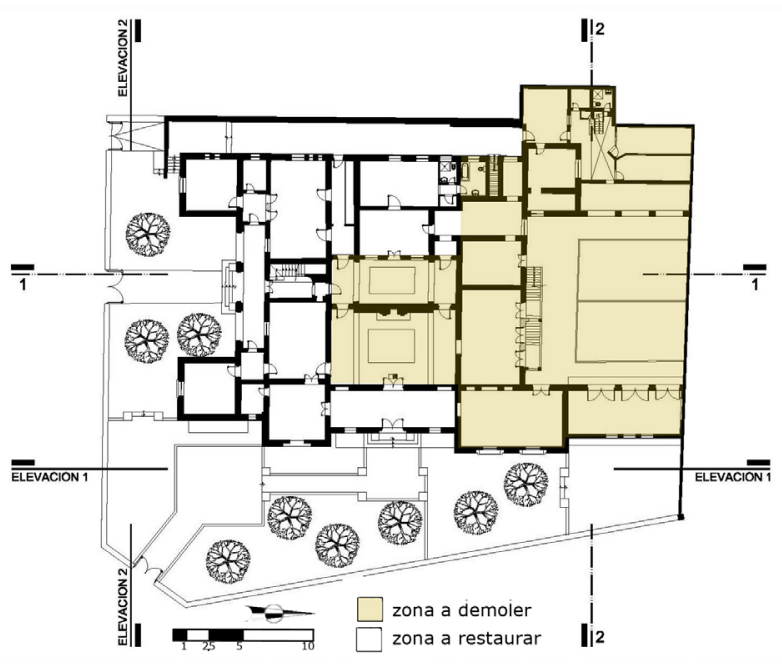

Figura 20. Planta preintervención. Fuente. Archivo personal Enrique Bonilla, 2015.

Figura 21. Planta posintervención. Fuente. Archivo personal Enrique Bonilla, 2015.

Figura 23. Molduras de yeso. Fuente. Archivo personal Enrique Bonilla, 2015.

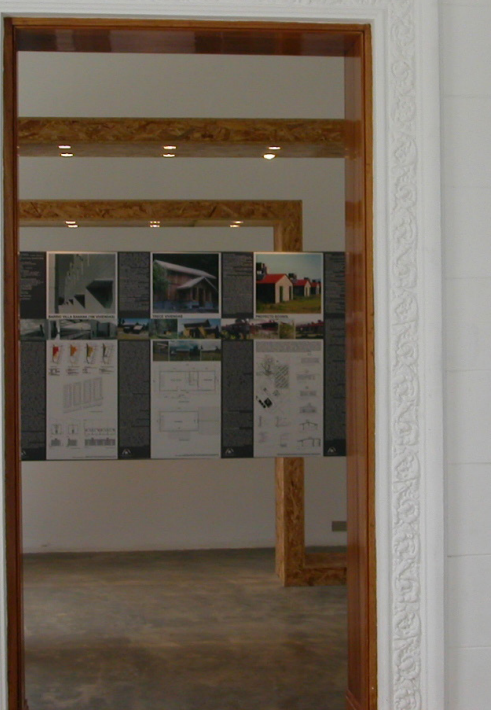

Probablemente la distribución natural de la casona habría dificultado en varios sentidos su adaptación a universidad, pues las circulaciones laberínticas entorpecerían el flujo de estudiantes y las proporciones de los ambientes difícilmente se podrían adecuar exitosamente como aulas de clase (Figuras 19 y 20).

Ante el abandono del que era objeto la casona, la Universidad Ricardo Palma decidió renovar su imagen institucional y desarrollar el proyecto centro cultural Ccori Wasi de la mano de la dupla de arquitectos Juvenal Baracco y Enrique Bonilla. Ambos consideraron que, por un lado, la casona aún contenía un valor sentimental en la memoria universitaria y que, por otro lado, no existía ningún título de intangibilidad que limite el universo de posibilidades de intervención. Por tanto, analizaron el inmueble e identificaron el carácter especial del conjunto urbano que la contenía, y planearon afianzar esta condición mediante la intervención. Así que, a partir de un estudio funcional y volumétrico, se planteó resaltar la belleza de la edificación antigua y reafirmar la morfología urbana existente (Figura 21).

La propuesta constituyó una obra mixta divisible en tres sectores: el primero pertenece a la parte del inmueble a conservar, el segundo consiste en obras nuevas insertadas en lo preexistente y el tercero constituye un volumen independiente (Figura 22).

Los trabajos de conservación empezaron con el reconocimiento y hallazgo de interesantes elementos neocoloniales. Los pisos, por su valor estético, fueron de especial interés, por lo que algunos se resanaron y otros se repusieron. Entre estos se encuentran losetas venecianas en los pisos y pasos de mármol repuestos en la escalera. Por otro lado, se deseaba conservar las decoraciones de yeso de las estancias interiores; para ello se retiraron las puertas existentes, que fueron reemplazadas por marcos de madera de diseño lineal. La intención era resaltar los ornamentos de las molduras contrastándolas con la simpleza de los nuevos marcos. Se hicieron trabajos de adaptación a los nuevos que expresan un lenguaje contemporáneo, diferente a lo conservado y restaurado (Figura 23).

La casona existente se componía de ambientes conectados pero no continuos; por consiguiente, se demolieron algunos muros para ampliar los ingresos y tener circulaciones más fluidas. Igualmente, se generaron nuevos vanos y se independizaron ingresos a la que fuera primero la cafetería y luego la tienda de libros, lo cual favoreció la flexibilidad de usos -independientes o no- del edificio general. No obstante, la mayor demolición tuvo lugar en los espacios centrales del edificio. 

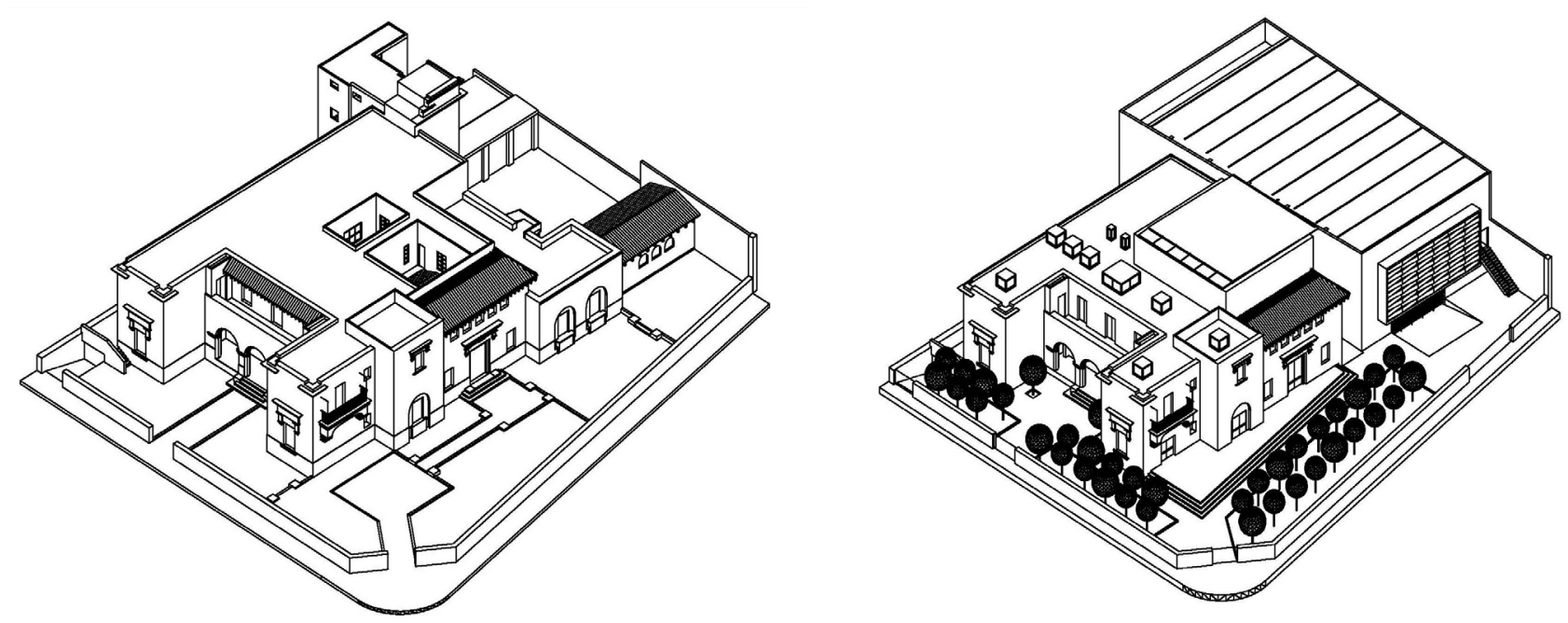

Para acomodar el programa era necesario generar dos espacios amplios para foyer y auditorio; sin embargo, no existía un espacio de esas medidas en el conjunto, por lo que se tuvo que demoler parcialmente el inmueble y algunos ambientes anexos a la casona, así como unas aulas precarias desengranadas al estilo neocolonial para insertar el auditorio (Figura 24).

La sala de usos múltiples -que sirve además como foyer del auditorio- es un cubo de estructura metálica y forro de trupán de 11 metros de lado. Sobre este se colocó el volumen destinado a la biblioteca, el cual consiste en un puente metálico con piel de vidrio suspendido en medio de dicha sala. Este elemento une ambos lados del edificio restaurado, y consolida zonas de circulación que distribuyen a aulas, oficinas y servicios en el segundo piso una carga para los muros de adobe existentes (Figura 25).

El auditorio también es una obra nueva: se trata de un volumen de concreto armado que encierra un auditorio para 200 personas. El volumen es de concreto expuesto de bruñas verticales y está cubierto parcialmente por una piel entramada de paños metálicos. Bajo este volumen se accede al estacionamiento independiente y hacia los lados funcionan circulaciones secundarias.

La propuesta busca generar un diálogo entre la edificación reciclada, la obra nueva y el entorno. Al recorrer la avenida Arequipa, se puede reconocer una morfología urbana particular, pues existe un ritmo constante entre las casonas y sus retiros frontales y laterales. Estos Ilenos y vacíos fueron asimilados en el proyecto a partir del juego de volúmenes. Es por ello que el auditorio está separado de la casona recuperada, a una distancia similar de la que la separa de la construcción vecina (Figura 26).

La intervención busca consolidar la morfología urbana en esa porción de ciudad, pues los arquitectos consideran, como señala la Carta de Venecia (1964), que es importante otorgar una importancia a los ambientes, los conjuntos arquitectónicos, el entorno y el urbanismo, haya en ellos monumentos o no.

En un inicio, las implicancias no favorecían la subsistencia de la casona. Por un lado, la edificación no era patrimonio arquitectónico declarado; por tanto, no existía una obligación jurídica para conservarla. Por otro lado, a juicio de los arquitectos, no poseía un valor histórico o artístico sustancial. No obstante, el análisis posterior demostraría que su presencia tiene un significado contundente como componente del contexto que lo rodea. De acuerdo a lo señalado en la Carta de Cracovia (2000) sobre los edificios que constituyen zonas urbanas de carga patrimonial, "pueden no tener ellos mismos
Figura 22. Axonometría preintervención.

Fuente. Archivo personal Enrique Bonilla, 2015

Figura 24. Axonometría posintervención.

Fuente. Archivo personal Enrique Bonilla, 2015 .

Figura 25. Vista interior.

Fuente. Archivo personal Enrique Bonilla, 2015.

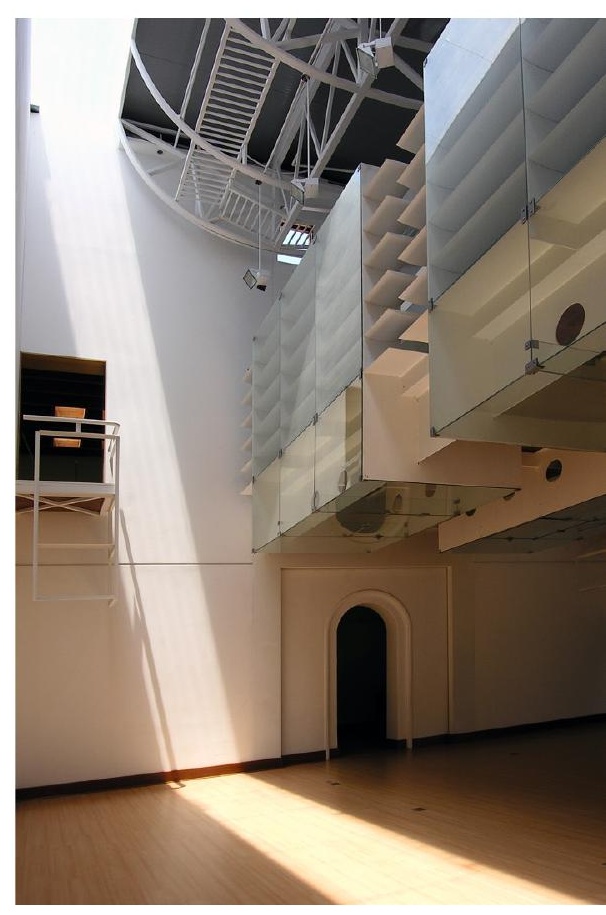




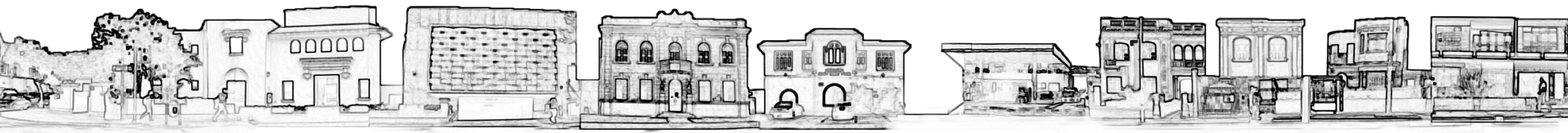

Figura 26. Morfología urbana (Av. Arequipa).

Fuente. Elaboración propia de la autora, 2015.

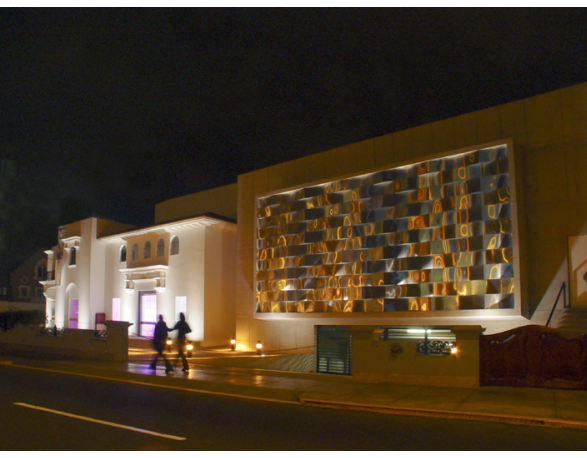

Figura 27. Vista exterior.

Fuente. Archivo personal Enrique Bonilla, 2015.

Figura 28. Panorámica posintervención.

Fuente. Archivo personal Enrique Bonilla, 2015. un valor arquitectónico especial, pero deben ser salvaguardados como elementos del conjunto por su unidad orgánica, dimensiones particulares y características técnicas, espaciales, decorativas y cromáticas insustituibles en la unidad orgánica de la ciudad" (p. 3). Aunque un grupo de edificaciones no sea un monumento, eso no significa que el conjunto urbano que las integra no pueda ser considerado como tal.

Acorde a dicho planteamiento, se pensaron detalles que contribuyan a unificar el proyecto al contexto circundante. Por ejemplo, para el auditorio se propuso un diseño en las bruñas del concreto expuesto que sea lineal y secuencial con el de la casona colindante, de manera que se relacione con el lenguaje de la edificación vecina. Asimismo, posee un diseño ondulante en la fachada que produce cambios en la percepción de la luz, pues varía de acuerdo al ángulo desde el que se esté mirando, de modo que durante la noche se genera un lenguaje contemporáneo entre la casona restaurada y la obra nueva (Figura 27).

El color es, finalmente, otro importante aspecto que se ha desarrollado en esta intervención. El concreto expuesto se integra con naturalidad a la edificación vecina, ya que los tonos de gris son similares, mientras que el color blanco en muros y cornisas aporta neutralidad a la propuesta, brindándole un carácter atemporal (Figura 28).

Los autores de esta intervención asumieron con audacia la relación con la ciudad, ya que la edificación se ha insertado en el contexto tomando en cuenta particularidades del lugar. La fachada de acero demuestra el carácter dinámico y vanguardista del distrito, mientras que una luz violeta aviva sus muros blancos y cornisas, y resalta la parte antigua. Este es un ejemplo adecuado de cómo "la generalización de las intervenciones es obsoleta, ya que cada edificio cuenta con una historia particular, un uso a albergar, un contexto en el que ubicarse y una relación con la ciudad que buscar" (Bonilla, comunicación personal, 16 de octubre de 2010).

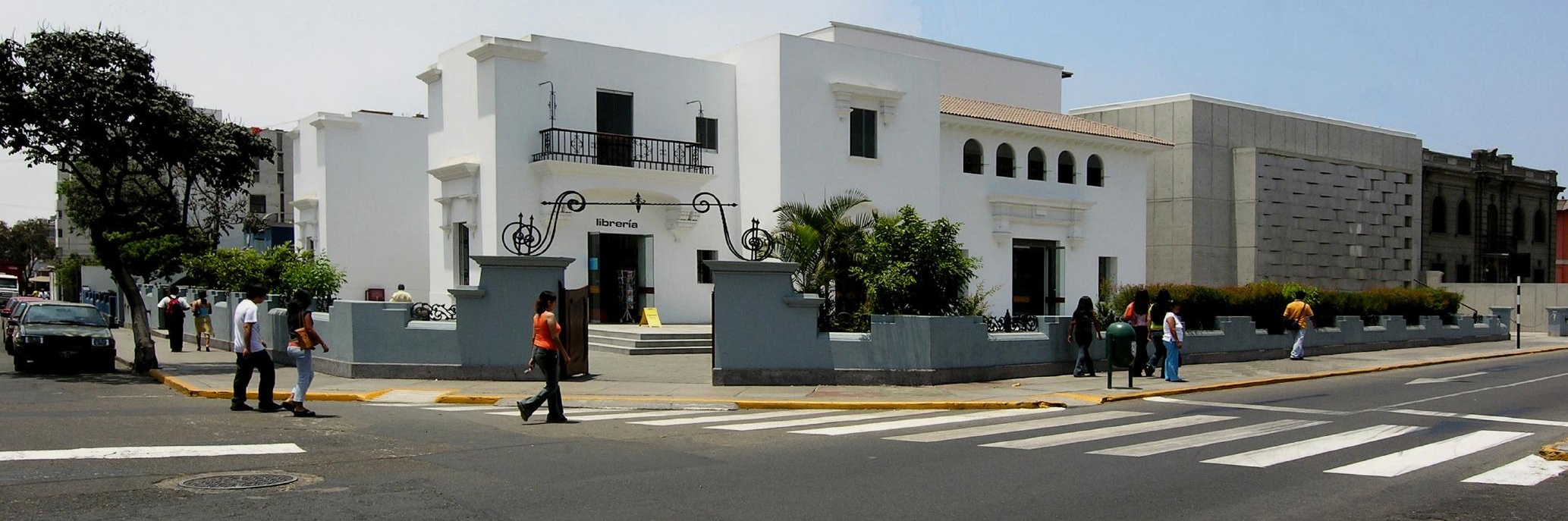




\section{Conclusiones}

Analizar tres casos tan disímiles permite conocer los factores que influyeron en las decisiones que cada arquitecto tomó. Se ha podido corroborar el discurso, la metodología, las intenciones y los logros, y también identificar los distintos factores que determinaron el carácter de la recuperación en cada caso.

Un factor decisivo es el promotor, pues define el carácter y enfoque de cada propuesta. La recuperación de la Casona de San Marcos es la única auspiciada por una entidad pública; por ello, el carácter social de la edificación es el tema de mayor envergadura en la intervención. En este caso, el diálogo entre arquitecto y promotor se hace más fluido, pues se privilegia la experiencia de los usuarios, lo que hace posible un mayor estudio de posibilidades y la elaboración de ideas innovadoras. Por otro lado, el patrocinio de entes privados se concentra en objetivos más prácticos. En el caso del centro cultural Ccori Wasi, la Universidad Ricardo Palma buscaba una renovación de imagen; por lo tanto, los autores pudieron desarrollar un diseño contemporáneo atrayente, aprovechando, también, que el inmueble no tenía ninguna protección patrimonialista. En el caso del Mercado de Barranco, dada la condición de monumentalidad existente, el ente privado comercial solicitó una intervención que requiera la menor inversión y tenga el mayor practicismo posible, a la par que satisfaga las leyes patrimoniales.

Efectivamente, cada promotor condiciona la propuesta desde el inicio. Si la inversión es pública, el carácter social de las edificaciones conformará cánones imperativos de innovación en la intervención, mientras que si de capitales privados se trata, la contribución se centra en el efecto urbano causado, como el mejoramiento del entorno urbano, o la consolidación de nuevos hitos y zonas urbanas patrimoniales.

Otro factor determinante es el contexto en el cual se ubica el inmueble. Los tres casos incluyen un enfoque urbano social en su discurso, orientado a generar interacciones con la ciudadanía. En el caso del centro cultural Cori Wasi, el edificio funciona como un dinamizador urbano, ya que su arquitectura resalta lo antiguo sobre lo nuevo, y lo transforma en un foco de interés. La imagen proyecta un carácter vanguardista que se intensifica mediante los efectos luminosos de la fachada metálica, el tránsito rápido de la avenida y el ojo del peatón. Esta relación elocuente es llamativa e interesante, pues tiene una expresión dinámica y contemporánea sin llegar a ser estruendosa.

En el Mercado de Barranco, los aportes urbanos se evidencian fuera de los límites del lote. La monumentalidad del mercado como hito urbano ha sido mejorada, pues el juego de luces pone en valor tanto los atributos de la arquitectura art déco como las casas, espacios públicos y comercios circundantes. De igual forma, muestra que desde la inversión privada posible conseguir una mejora emocional de los vecinos mediante la revitalización del espacio urbano.

Por su parte, el la Casona de San Marcos involucra una lógica urbana de mayor envergadura, pues se enfrenta al Parque Universitario, importante espacio público. Así, la intervención incluyó el desarrollo de un circuito didáctico a partir de los descubrimientos hechos durante los procesos de intervención, interesante estrategia para incitar al ciudadano a usar el edificio. Sin embargo, la vocación cultural de la casona tiene un potencial mayor aún: el Parque Universitario podría integrarse al circuito educativo. Plantear un diálogo entre monumento y espacio público es un tema pendiente.

El siguiente factor relevante es el manejo de los principios de la restauración en cada intervención. El marco teórico indica las pautas específicas que deben seguirse para lograr la correcta intervención en un monumento; sin embargo, los distintos factores implicados pueden dificultar su aplicación en la realidad local. El panorama limeño se encuentra plagado de trabas económicas e institucionales, los recursos y promotores son escasos, y los movimientos telúricos desafían las obras constantemente. 
Por ello, los autores suelen transigir al tomar decisiones, y se otorgan ciertas libertades dependiendo del valor que tengan las edificaciones. De esta manera, la carga teórica ortodoxa se ha flexibilizado, lo cual permite ampliar criterios y visiones sin soslayar los fundamentos esenciales de la restauración de monumentos.

En todos los casos estudiados se aplicaron cánones teóricos tangentes al de la Carta de Venecia. En cuanto a la Casona de San Marcos, la valoración del factor histórico permite compatibilizar la propuesta con la teoría del Restauro Científico: se realizó un esfuerzo por diferenciar lo nuevo de lo antiguo, suprimiendo adornos en los elementos nuevos. Por otro lado, los criterios aplicados en el caso del Mercado de Barranco poseen similitudes con los dictámenes del Restauro Crítico, pues la labor se enfocó en recuperar el valor artístico del edificio. Finalmente, en la recuperación del centro cultural Ccori Wasi, el concepto se planteó sobre la base de los cánones descritos en la Carta de Venecia, luego reafirmados por otros escritos como la Carta de Cracovia (2000), pues afirma la validez del rescate de una zona urbana a partir de las edificaciones cuyo valor como monumentos no es indispensable.

Las tres propuestas aplican criterios de diferenciación de lo antiguo y lo nuevo, como estipularía la restauración científica, disciplina que indica que las intervenciones constructivas deben diferenciarse mediantes el contraste, es decir, utilizando materiales modernos, suprimiendo los ornamentos o ciñéndose a la simplicidad geométrica. De esta manera, la contraposición entre lo nuevo y lo antiguo conformaría un diálogo donde el pasado es enfatizado a través del contraste con lo presente.

No obstante la validez teórica de estas premisas, este criterio sería criticado por el autor Ignasi de Solà-Morales, quien prefiere utilizar la analogía en vez del contraste, pues considera que este resalta más efectivamente las características del inmueble original. Según Solà-Morales (2006), la analogía, en tanto ejercicio de reconocimiento de las estructuras significativas del material histórico existente, debe utilizarse como pauta para el nuevo artefacto edificado, ya que esta abre un abanico infinito de posibilidades. Aplicar la analogía supone identificar los rasgos dominantes del edificio y luego, mediante un ejercicio analógico, transmitirlos a la propuesta. Se trata de un ejercicio más complejo que el contraste, el cual simplemente consiste en utilizar un material o lenguaje opuesto al existente.

Tanto en el caso barranquino como el sanmarquino, se identificaron intervenciones por contraste. En el primer caso, por la diferenciación material de las nuevas columnas; en el segundo caso, por la supresión de ornamentos. Sin embargo, en el caso miraflorino, el contraste entre la casona antigua y la obra nueva es más complejo, pues se interpretan proporciones y alturas, tanto del inmueble existente como de las casonas contiguas. Si bien existe un contraste entre materialidades y composición, también es legible un intento análogo con resultado armonioso.

Sin duda alguna, la recuperación del centro cultural Ccori Wasi pudo realizarse con mayor libertad debido a que partió de una iniciativa de la universidad, no una exigencia jurídica patrimonial. Ya que no había sido declarado inmueble patrimonial, las acciones para intervenirlo fueron materia únicamente del arquitecto y el promotor. Esto no sucedió en los otros dos casos: ambos habían sido declarados patrimonio monumental, lo que obligaba a incluir al INC como ente regulador y revisor. Dicha entidad, cuya labor era velar por el patrimonio, no cumplía el rol promotor necesario y sus criterios de dirección técnica eran muy generales. Según los autores de las obras, en general, dichos criterios eran de carácter técnico, lo cual no permitía el análisis independiente de cada caso ni la discusión igualitaria sobre innovaciones en la intervención en el patrimonio. 
Según Fernández (1999), uno de los impulsos restauradores es el valor evocativo que pueden proyectar los objetos. Esta búsqueda de promover una relación entre el sujeto de hoy y el objeto histórico a través de la memoria es común a los tres casos de manera espontánea: el aura de los patios sanmarquinos, donde la intención conservativa y de mejoramiento mantiene la naturaleza del edificio; el techo del Mercado de Barranco, donde el detalle de coberturas, y la relación materialidad y luz del día recuerdan un viejo mercado espontáneo; y el barrio miraflorino, conjunto de casonas neocoloniales en un armonía urbana. Estas son estímulos que cada autor buscó remarcar.

En conclusión, la metodología de acercamiento a la intervención es similar en los tres casos. En primer lugar, cada edificio se estudió y analizó para conocer su estado físico de conservación, e identificar sus atributos artísticos e históricos, siguiendo los principios de la Carta de Venecia. Luego, teniendo en cuenta las variables económicas, urbanas y normativas, y entendiendo al edificio desde su matriz, se emitió un juicio crítico para determinar el carácter de la intervención. El objetivo fue, finalmente, generar una propuesta viable que concilie los elementos que debían ser conservados con los requerimientos que imponía el nuevo uso, de forma que sea un aporte a la ciudad.

No existe una manera definitiva cómo intervenir en el patrimonio arquitectónico de Lima, ya que no existen normativas específicas desarrolladas por las entidades pertinentes. El balance final muestra que el carácter de cada restauración se centró en el juicio y la toma de decisiones personal, ya que el entonces INC funcionaba solo como una entidad supervisora. Debido a esta ausencia, los arquitectos han ido flexibilizando sus criterios, pues al intentar aplicar el discurso de forma ortodoxa a la realidad se toparían con supervisores inflexibles. No obstante, las soluciones finales están en las manos del proyectista, pues una explicación racional y sustentada debería ser considerada. Ante la ausencia de un consenso sobre cómo realizar las intervenciones en edificios patrimoniales, el desarrollo del campo de la conservación y restauración ha estado fuertemente ligado al personal humano en el contexto limeño (Hayakawa, 2001).

Ante este escenario, en el que no está definido cuál es el correcto quehacer para asegurar la conservación del patrimonio, es inquietante pensar en cómo se lleva a cabo la protección del patrimonio en el resto del país. Por ello, la actual Dirección de Cultura, anteriormente INC, tiene una importante labor pendiente en el campo de la salvaguarda del patrimonio edificado.

Por un lado, aún existe una valoración excesiva de la arquitectura virreinal sobre la perteneciente a otros momentos de la historia; la arquitectura prehispánica o moderna aún está al margen del imaginario de los peruanos, salvo casos aislados. Para suplir esta falta, es necesario recopilar información para completar el listado de patrimonio nacional, pues solo conociendo la amplitud de variables que lo constituyen será posible definir los niveles de intervención de acuerdo a su categoría.

La presente investigación permitió encontrar vacíos que la Dirección de Cultura debe suplir. En primer lugar, está el nexo con los promotores: debe generar estrategias que propicien facilidades a los interesados en invertir en el patrimonio edificado. En segundo lugar, mejorar la relación con los ciudadanos con el patrimonio, para lo cual podría establecer una red cultural de integración que permita conocer y difundir el valor de cada artefacto a conservar. Finalmente, hace falta aprender de las experiencias foráneas, estudiar las buenas prácticas desarrolladas en realidades similares a la peruana. En conclusión, corresponde a la Dirección de Cultura constituir un rol activo y convertirse en un verdadero gestor del patrimonio, como primer paso. 
devenir Vol. 2, N³, ENERO- JUNIO 2015, PP. 45-62 - EsTUDIOS | ISSN 2312-7570

UNIVERSIDAD NACIONAL DE INGENIERÍA, LIMA

\section{Referencias}

Bonilla, T. E. \& Fuentes, H. M. C. (2009). Lima y el Callao: Guía de arquitectura y paisaje. Lima, Perú: Universidad Ricardo Palma.

Burneo, R. A. (2005). Orígenes y evolución del conjunto arquitectónico de la Casona de San Marcos. Lima, Perú: Programa para la Conservación del Patrimonio Cultural.

Cerna, D. (2007). Reeditar el patrimonio. Escala, 213(1), 14-15.

Fernández, A. (1999). El proyecto moderno de la arquitectura en los territorios del patrimonio histórico. Cuadernos del instituto Juan de Herrera de la Escuela de Arquitectura de Madrid 1, 1-5.

Hayakawa, J. C. (2001). La restauración en Lima: Pasos y contrapasos (Tesis de pregrado). Universidad Nacional de Ingeniería, Lima, Perú.

Consejo Internacional de Monumentos y Sitios (ICOMOS). (1964). Carta de Venecia.

Consejo Internacional de Monumentos y Sitios (ICOMOS). (2000). Carta de Cracovia.

Instituto Nacional de Cultura. (2008). ¿Qué es patrimonio cultural? Lima, Perú: Autor.

Solà-Morales, I. (2006). Intervenciones. Barcelona, España: Gustavo Gili. 